Article

\title{
Thermal Stability of Type II Modifications by IR Femtosecond Laser in Silica-based Glasses
}

\author{
Shu-En Wei ${ }^{1}$, Yitao Wang ${ }^{2, *}$, Heng Yao ${ }^{2}$, Maxime Cavillon ${ }^{2} \oplus$, Bertrand Poumellec ${ }^{2}$, \\ Gang-Ding Peng ${ }^{1}$ and Matthieu Lancry ${ }^{2, *}$ \\ 1 Photonics and Optical Communications Group, School of Electrical Engineering, University of New South \\ Wales, Sydney, NSW 2052, Australia; shuen.wei@unsw.edu.au (S.-E.W.); g.peng@unsw.edu.au (G.-D.P.) \\ 2 Institut de Chimie Moléculaire et des Matériaux d'Orsay, Université Paris Saclay, 91400 Orsay, France; \\ heng.yao22021992@gmail.com (H.Y.); maxime.cavillon@u-psud.fr (M.C.); \\ bertrand.poumellec@u-psud.fr (B.P.) \\ * Correspondence: yitao.wang@u-psud.fr (Y.W.); matthieu.lancry@u-psud.fr (M.L.); Tel.: +33-169156218
}

Received: 9 January 2020; Accepted: 27 January 2020; Published: 30 January 2020

check for updates

\begin{abstract}
Femtosecond (fs) laser written fiber Bragg gratings (FBGs) are excellent candidates for ultra-high temperature $\left(>800{ }^{\circ} \mathrm{C}\right)$ monitoring. More specifically, Type II modifications in silicate glass fibers, characterized by the formation of self-organized birefringent nanostructures, are known to exhibit remarkable thermal stability around $1000{ }^{\circ} \mathrm{C}$ for several hours. However, to date there is no clear understanding on how both laser writing parameters and glass composition impact the overall thermal stability of these fiber-based sensors. In this context, this work investigates thermal stability of Type II modifications in various conventional glass systems (including pure silica glasses with various $\mathrm{Cl}$ and $\mathrm{OH}$ contents, $\mathrm{GeO}_{2}-\mathrm{SiO}_{2}$ binary glasses, $\mathrm{TiO}_{2}$ - and $\mathrm{B}_{2} \mathrm{O}_{3}$-doped commercial glasses) and with varying laser parameters (writing speed, pulse energy). In order to monitor thermal stability, isochronal annealing experiments $\left(\Delta \mathrm{t} \sim 30 \mathrm{~min}, \Delta \mathrm{T} \sim 50{ }^{\circ} \mathrm{C}\right)$ up to $1400{ }^{\circ} \mathrm{C}$ were performed on the irradiated samples, along with quantitative retardance measurements. Among the findings to highlight, it was established that ppm levels of $\mathrm{Cl}$ and $\mathrm{OH}$ can drastically reduce thermal stability (by about $200{ }^{\circ} \mathrm{C}$ in this study). Moreover, $\mathrm{GeO}_{2}$ doping up to $17 \mathrm{~mole} \%$ only has a limited impact on thermal stability. Finally, the relationships between glass viscosity, dopants/impurities, and thermal stability, are discussed.
\end{abstract}

Keywords: fiber Bragg gratings (FBGs); thermal stability; Type II modification; femtosecond laser; silica-based glasses

\section{Introduction}

Over the past 10 years, development of high temperature optical fiber-based sensors, such as fiber Bragg gratings (FBGs), has drawn great attention due to their wide range of applications, including temperature profiling of equipment in manufacturing industry like smelters or laser additive manufacturing [1], monitoring temperature and strain in oil, gas and geothermal industries [2], or again temperature and pressure monitoring in next generation sodium cooled nuclear reactors, airplanes engines, etc.

Conventional FBGs typically are inscribed into fibers composed of germanium-doped silica cores, due to their photosensitivity under intense ultraviolet (UV) light irradiation [3]. Under such irradiation, point defects are created inside the glass core, yielding changes in the glass macroscopic properties such as density and refractive index. These refractive index changes are positive with respect to the pristine (i.e., non-irradiated) glass and are often referred to as Type I index change [4]. When UV-induced refractive index changes are chosen as a way to inscribe photonic devices (i.e., Type I Bragg 
grating sensors), the later can only be used up to $\sim 450{ }^{\circ} \mathrm{C}$. Above this temperature, the imprinted object would progressively be thermally erased, making Type I Bragg grating sensors no longer suitable for temperature monitoring [5]. To go beyond the thermal limitations imposed by the technology described above, it is possible to imprint other kinds of modifications in the glass that can withstand higher temperature operation. One possibility is to make femtosecond Type II fiber Bragg gratings (also referred to Type II fs-FBGs) [5,6]. As opposed to Type I refractive index change, the Type II modification corresponds to the formation of nanostructures in most silica-based glasses associated with a high level of anisotropic index change [7]. It has been demonstrated that Type II fs-FBGs exhibited thermal stability at $\sim 1000{ }^{\circ} \mathrm{C}$ for at least several hours in silica [8,9] and up to $150 \mathrm{~h}$ provided the FBGs have been stabilized [5,6].

Additionally, it is important to point out that both the structural characteristics of the fs-Type II modification and its thermal stability are both dependent on the fiber core glass composition. In fiber fabrication processes, germanium oxide $\left(\mathrm{GeO}_{2}\right.$, typically up to 30 mole percent) is arguably the most common fiber core dopant and is used to increase the refractive index of the core relative to the one of the cladding material (being silica, $\mathrm{SiO}_{2}$ ) in order to form a guiding core [10]. In addition to $\mathrm{GeO}_{2}$, other common dopants such as fluorine $(\mathrm{F})$, aluminum oxide $\left(\mathrm{Al}_{2} \mathrm{O}_{3}\right)$, boron oxide $\left(\mathrm{B}_{2} \mathrm{O}_{3}\right)$, and titanium dioxide $\left(\mathrm{TiO}_{2}\right)$ also are incorporated into the fiber, and this for different purposes [11-13]. For example, we recently investigated "high temperature fibers" composed of aluminosilicate cores made by the molten core method [4]. For the $\mathrm{Y}_{2} \mathrm{O}_{3}-\mathrm{Al}_{2} \mathrm{O}_{3}-\mathrm{SiO}_{2}$ core composition, the measured birefringence does not decrease when tested up to $100{ }^{\circ} \mathrm{C}$ for $30 \mathrm{~min}$, while for the $\mathrm{SiO}_{2} \mathrm{~F} 300$ cladding it decreased by $\sim 30 \%$. These results suggest that inscription of "Type II $f_{s}-I R$ " modifications in such fibers could be employed to make FBGs with high thermal stability and to potentially overcome the current performances of pure silica core or Ge-doped $\mathrm{SiO}_{2}$ fibers. During the incorporation of dopants or along the fabrication process, impurities such as chlorine $(\mathrm{Cl})$ and hydroxyl groups $(\mathrm{OH})$ are also inevitably introduced $[14,15]$. All these intended incorporated elements or unintended contaminations would influence the formation of fs-Type II modifications and their thermal stability. To date, the relevant research on the impact of these incorporated elements/impurities on the formation of fs-Type II modification and thermal stability is sparse and not systematic [4,16-20].

In addition to the material, laser-writing process has been proved to be another important factor influencing the thermal performance of FBGs. It has been theoretically shown that thermal stability of FBGs can be enhanced by increasing the writing time [21], while the effect of pulse intensity and repetition rate on the thermal performance of FBGs has been investigated elsewhere (Reference [22]). However, to date there is no clear understanding on how both laser writing parameters and glass composition impact the overall thermal stability of these fiber-based sensors. Consequently, it prevents reliable lifetime and performance predictions of the fabricated objects, as the underlying mechanisms of erasure at high temperatures are not well identified.

It is not convenient to carry out a controlled and systematic research work by directly using fibers, because of their (usually) small core sizes along with the variety of their fabrication processes. In addition, to ensure a good quality of the irradiations and accuracy of measurements, homogeneous glass samples, rather than fiber samples, which have gradient distributed dopants concentration in their cores, are preferred in the present study. Consequently, in this work, the formation of fs-Type II modifications and their thermal stability in silica-based bulk glasses, instead of fibers, are investigated. More specifically, the impact of the writing conditions, especially writing speed, on fs-Type II modification thermal stability, is studied. Furthermore, we investigate the impact of impurities $(\mathrm{Cl}$ and $\mathrm{OH})$ and dopants $\left(\mathrm{GeO}_{2}, \mathrm{TiO}_{2}\right.$ and $\left.\mathrm{B}_{2} \mathrm{O}_{3}\right)$ on fs-Type II modification thermal stability. This work is expected to help in the future high temperature fiber sensor designs based on investigated oxide glass compositions. 


\section{Materials and Methods}

In order to investigate the impact of the laser writing speed on thermal stability of fs-Type II modifications, a standard grade fused silica sample from Heraeus (Suprasil CG ${ }^{\circledR}$ ) was chosen.

To study the impact of composition on thermal stability, several sets of optical glasses are investigated. The samples are silica glasses with different $\mathrm{Cl}$ and $\mathrm{OH}$ concentrations in them (which are considered impurities as mentioned above). More specifically, we investigated Type I (Infrasil $\left.301^{\circledR}\right)$, Type II (Homosil ${ }^{\circledR}$ ), Type III (Suprasil CG ${ }^{\circledR}$ and Spectrosil 2000 ${ }^{\circledR}$ ), and Type IV (Suprasil F300 ${ }^{\circledR}$ ) silica glasses. The second set of samples is composed of 4 germanosilicate $\left(\mathrm{SiO}_{2}-\mathrm{GeO}_{2}\right)$ glasses with $\mathrm{GeO}_{2}$ concentration ranging from 1.9 to 16.9 mole\%. These $\mathrm{SiO}_{2}-\mathrm{GeO}_{2}$ glasses, all with low $\mathrm{OH}$ content $(<0.1 \mathrm{ppm}$ ) and high $\mathrm{Cl}$ content (typ. $2000 \mathrm{ppm}$ ), were manufactured by chemical vapor deposition (CVD) method. Finally, the last set of samples includes four silicate glasses doped with different oxide components (among which $\mathrm{TiO}_{2}, \mathrm{GeO}_{2}, \mathrm{~B}_{2} \mathrm{O}_{3}$ ) and one fused silica glass for sake of comparison. More specifically, these samples are Infrasil $301^{\circledR}$ for the silica one, two germanosilicate glasses, one $\mathrm{TiO}_{2}$-doped silica (ULE ${ }^{\circledR}$, Corning), and one alumino-borosilicate glass (Schott Borofloat $33^{\circledR}$ ).

To help the reader, Table 1 summarizes the glass samples investigated in this study, along with their compositions, impurity types and concentrations, and annealing temperature $\left(\mathrm{T}_{\mathrm{a}}\right.$, defined as the temperature at which the viscosity is $\left.10^{13} \mathrm{dPa} \cdot \mathrm{s}\right)$. The latter will be helpful during the discussion of the results.

Table 1. Designations, compositions, impurities ${ }^{1}$, and $\mathrm{T}_{\mathrm{a}}{ }^{2}$ of samples for each section.

\begin{tabular}{|c|c|c|c|c|c|}
\hline \multirow{2}{*}{ Section } & \multirow{2}{*}{ Designations } & \multirow{2}{*}{ Compositions(mole\%) } & \multicolumn{2}{|c|}{ Impurities $^{1}$ (ppm) } & \multirow{2}{*}{$\begin{array}{l}\mathrm{T}_{\mathrm{a}}{ }^{2} \\
\left({ }^{\circ} \mathrm{C}\right)\end{array}$} \\
\hline & & & $\mathrm{OH}$ & $\mathrm{Cl}$ & \\
\hline $\begin{array}{c}3.1 \\
\text { Speed }\end{array}$ & Suprasil CG ${ }^{\circledR}$ & $100 \mathrm{SiO}_{2}$ & 830 & $<2500$ & 1100 \\
\hline \multirow{5}{*}{$\begin{array}{c}3.2 \\
\mathrm{OH} ; \mathrm{Cl}\end{array}$} & Type I (Infrasil 301 ${ }^{\circledR}$ ) & \multirow{5}{*}{$100 \mathrm{SiO}_{2}$} & 8 & $<0.15$ & 1180 \\
\hline & Type II (Homosil@) & & 380 & $<1$ & 1180 \\
\hline & Type III (Suprasil CG ${ }^{\circledR}$ ) & & 830 & $<2500$ & 1100 \\
\hline & $\begin{array}{l}\text { Type III (Spectrosil } \\
\left.2000^{\circledR}\right)\end{array}$ & & $800-1200$ & $<0.15$ & 1025 \\
\hline & Type IV (Suprasil F300 ${ }^{\circledR}$ ) & & 0.1 & 2500 & 1110 \\
\hline $\begin{array}{c}3.3 \\
\mathrm{GeO}_{2}\end{array}$ & Germanosilicate & $\begin{array}{c}x \mathrm{GeO}_{2}-(1-x) \mathrm{SiO}_{2}, x=1.9 \\
5,11.8,16.9\end{array}$ & $<0.1$ & $\sim 2000$ & $990-1090$ \\
\hline \multirow{5}{*}{$\begin{array}{c}3.4 \\
\text { Dopants }\end{array}$} & Infrasil 301 ${ }^{\circledR}$ & $100 \mathrm{SiO}_{2}$ & 8 & $<0.15$ & 1180 \\
\hline & Germanosilicate & $1.9 \mathrm{GeO}_{2}-98.1 \mathrm{SiO}_{2}$ & $<0.1$ & $\sim 2000$ & 1090 \\
\hline & Germanosilicate & $16.9 \mathrm{GeO}_{2}-83.1 \mathrm{SiO}_{2}$ & $<0.1$ & $\sim 2000$ & 990 \\
\hline & ULE corning $^{\circledR}$ & $7 \mathrm{TiO}_{2}-93 \mathrm{SiO}_{2}$ & - & - & 900 \\
\hline & Borofloat $33^{\circledR}$ & $\begin{array}{c}81 \mathrm{SiO}_{2}-13 \mathrm{~B}_{2} \mathrm{O}_{3}-4 \\
\mathrm{Na}_{2} \mathrm{O} / \mathrm{K}_{2} \mathrm{O}-2 \mathrm{Al}_{2} \mathrm{O}_{3}\end{array}$ & - & - & 663.6 \\
\hline
\end{tabular}

The laser used in this study was a commercial Yb-doped fiber amplifier femtosecond laser (Satsuma, Amplitude Systèmes Ltd. Pessac, France.), and the experimental conditions of laser inscriptions were the following: laser operating at $1030 \mathrm{~nm}, 250 \mathrm{fs}$ delivering pulses, and $100 \mathrm{kHz}$ repetition rate. The laser beam was focused at a depth of $200 \mu \mathrm{m}$ using a 0.6 NA aspheric lens (estimated beam waist $w \sim 1.5 \mu \mathrm{m}$ ) with the incident beam set perpendicular to the surface of the sample. The samples are affixed to a translation stage, which can be moved in the three dimensions of space, and the direction of the linear polarization was controlled using a $\lambda / 2$ waveplate mounted on a rotation stage. 
To understand how glass composition influences laser-induced modifications and thermal stability, a series of squares were inscribed with a femtosecond laser in glass samples mentioned above. For each inscribed square, the laser writing direction is set to be the $X$ axis, and the laser light polarization is oriented either parallel (Xx configuration, //) or perpendicular (Xy configuration, $\perp$ ) to it. Then, using a scanning speed $v$, we created several squares $0.1 \times 0.1 \mathrm{~mm}^{2}$, made up of a set of lines with a line spacing $\Delta y=1 \mu \mathrm{m}$ to have a uniform anisotropic area and avoiding any diffraction effects. Scheme about the laser writing procedure is shown in Figure 1 and more details can be found in Reference [23].

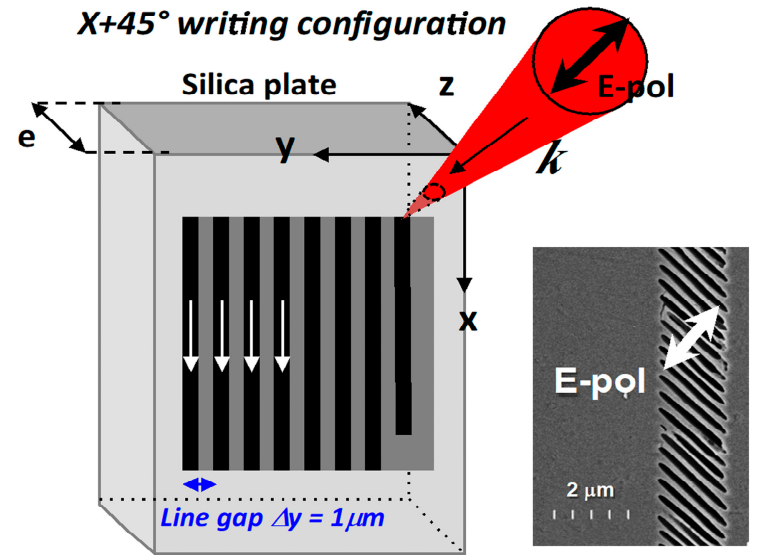

(a)

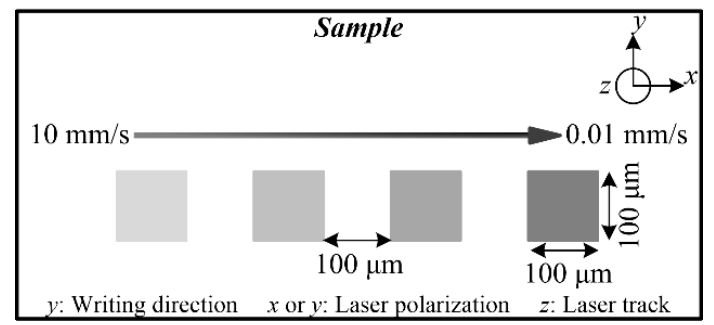

(b)

Figure 1. (a) Experimental setup scheme for $X+45^{\circ}$ writing configuration and SEM image of sub-wavelength periodic structure formed along a single irradiated line. Original image is courtesy of Dr. Cyril Hnatovsky. (b) Experimental laser writing design.

As pulse energy used during laser irradiation is set to be above the fs-Type II modification threshold (T2), the index change of irradiated regions is highly anisotropic, and its magnitude can be as large as $10^{-2}$ [16]. Such index change demonstrates thermal stability at $1000^{\circ} \mathrm{C}$ for a few hours [9], which is a critical advantage for its high temperature application. According to previous research, fs-Type II modifications of $\mathrm{SiO}_{2}$ (Suprasil $\mathrm{CG}^{\circledR}$ ) happen above an energy threshold of $0.4 \mu \mathrm{J}$ for laser polarization parallel to the laser scanning $\left(\lambda=1030 \mathrm{~nm}, \Delta \mathrm{t}_{\mathrm{p}}=300 \mathrm{fs}, \mathrm{RR}=100 \mathrm{kHz}\right.$, and NA $\left.=0.6\right)$ [24]. Therefore, in order to study the writing kinetic of type-II modifications, we performed the experiments by varying pulse energy from $0.3 \mu \mathrm{J}$ to $4 \mu \mathrm{J}$. In order to study the impact of the writing speed on thermal stability, the scanning speed $v$ was adjusted from 0.1 to $10 \mathrm{~mm} / \mathrm{s}$.

After femtosecond laser irradiation, the amount of optical retardance $(R)$, induced by laser irradiation, was measured with an Olympus BX51 polarizing optical microscope equipped with a "De Sénarmont" compensator. The compensator couples a high precision quarter waveplate (made of quartz) with a 180-degree rotating analyzer to provide retardation measurements, yielding an accuracy of retardation measurements that approaches one thousandth of the wavelength [25]. The retardance is defined as $R=B \times l$, where $B$ is the linear birefringence (typ. $\mathrm{n}_{\mathrm{e}}-\mathrm{n}_{\mathrm{o}}$ ) and $l$ is the thickness of the birefringent layer inscribed by the laser (and often corresponds to the laser track length expressed in $\mathrm{nm})$. Hence, when a laser irradiates a sample and a birefringent object is formed, the measured $R$ value corresponds to the amount of $B$ integrated over the laser track length (in the $z$ direction from Figure 1 ).

Moreover, the sample cross sections were investigated using a Scanning Electron Microscope (FEG-SEM, Field-Emission Gun Scanning Electron Microscope, ZEISS SUPRA 55 VP, 1 kV accelerating voltage, Oberkochen, Germany) after cleaving the samples using a diamond pen.

To investigate the thermal stability of the written fs-Type II modifications, the samples were isochronally ( $\delta t=30 \mathrm{~min}$ step) heat treated with an incremental increase (typ. $\Delta T=50{ }^{\circ} \mathrm{C}$ ) of temperature $\mathrm{T}$ up to $1400^{\circ} \mathrm{C}$. After each annealing step, retardance $R$ of the squares was measured at 
room temperature after natural cooling and normalized with respect to the retardance value from the as-irradiated glass.

\section{Results}

\subsection{Impact of the Writing Speed}

Figure 2a displays the normalized retardance $\left(R_{\text {norm }}\right)$ as a function of isochronal annealing temperature for a $\mathrm{SiO}_{2}$ sample from Heraeus (Suprasil $\mathrm{CG}^{\circledR}$ ), with different writing speeds, namely: $0.01 \mathrm{~mm} / \mathrm{s}, 0.1 \mathrm{~mm} / \mathrm{s}, 1 \mathrm{~mm} / \mathrm{s}$, and $10 \mathrm{~mm} / \mathrm{s}$. In this experiment, the pulse energy was set to $2.0 \mu \mathrm{J} / \mathrm{pulse}$. In addition, retardance values as a function of writing speed for the non-heat-treated samples were measured and are reported in the inset graph of Figure 2a. It shows that with the higher writing speed, the lower retardance value would be achieved, and agrees well with the tendency reported in Reference [26]. From Figure 2a, some common features can be found. First, there is a slight decrease in the normalized retardance value from $400{ }^{\circ} \mathrm{C}$ to $600{ }^{\circ} \mathrm{C}$ corresponding approximately to $10 \%$ decay of the retardance strength. This feature might be attributed, according to the literature, to the erasure of point defects centers ( $\left.\mathrm{E}^{\prime}, \mathrm{ODC}, \mathrm{NBOHC}\right)$ [27]. In the $800-1000^{\circ} \mathrm{C}$ temperature range, the faster decay of normalized retardance was found for low writing speeds $(0.01 \mathrm{~mm} / \mathrm{s}$ and $0.1 \mathrm{~mm} / \mathrm{s})$. This decline might be related to the erasure of Si-O three and four-fold rings at $800-900{ }^{\circ} \mathrm{C}[4,27]$ related to the relaxation of glass densification (Type I contribution) or of the strong compressive stress. Finally, for annealing temperature above $1000{ }^{\circ} \mathrm{C}$, a very steep decrease of the birefringence is observed. $R_{\text {norm }}(T)$ reaches zero at $\sim 1175{ }^{\circ} \mathrm{C}$ for all samples.

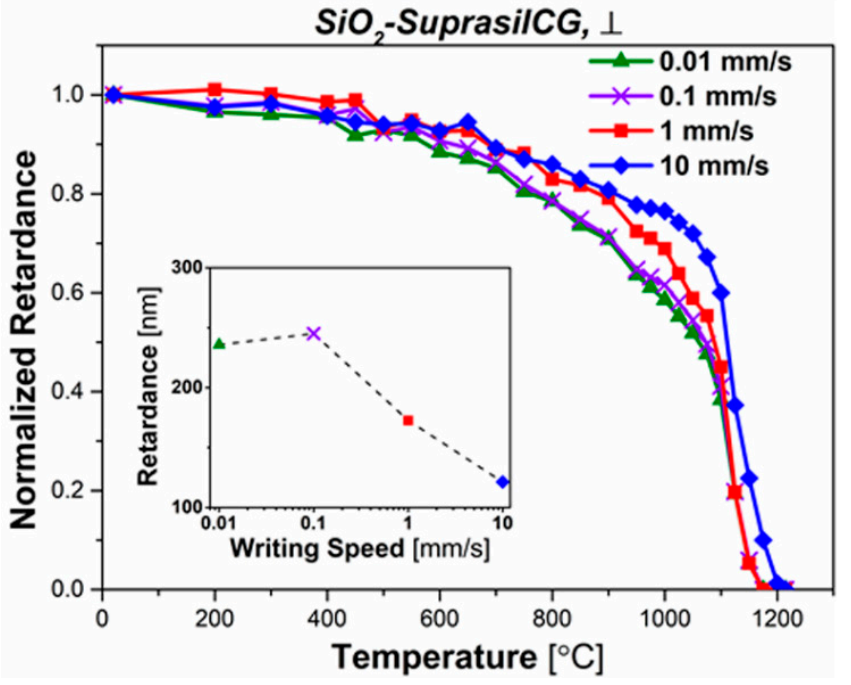

(a)

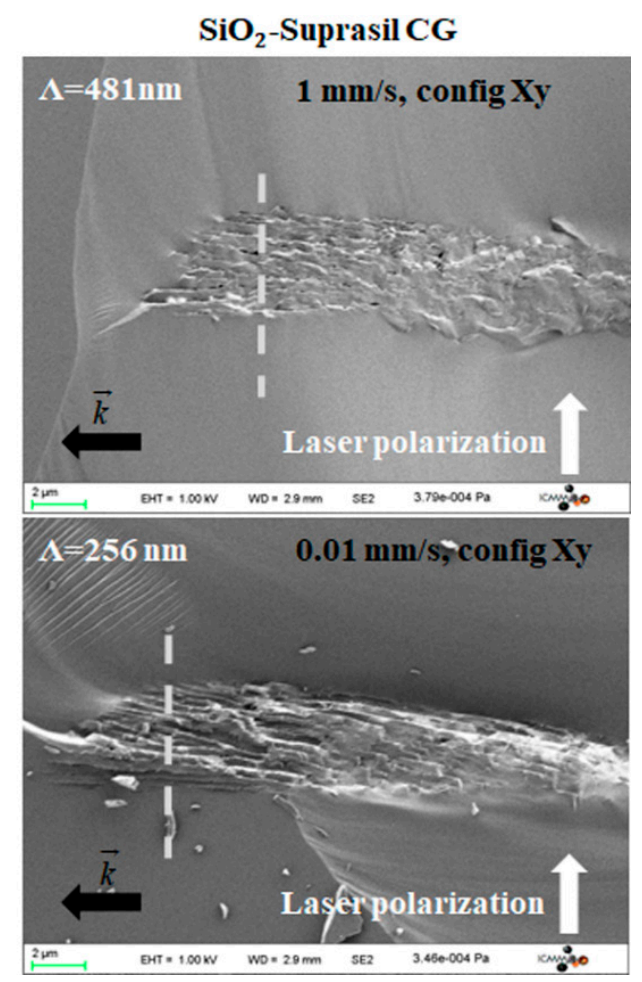

(b)

Figure 2. (a) Normalized retardance $\left(R_{\text {norm }}\right)$ as a function of temperature for $\mathrm{SiO}_{2}$ (Suprasil CG ${ }^{\circledR}$ ) samples inscribed by different writing speed $(0.01 \mathrm{~mm} / \mathrm{s}, 0.1 \mathrm{~mm} / \mathrm{s}, 1 \mathrm{~mm} / \mathrm{s}$, and $10 \mathrm{~mm} / \mathrm{s})$. The other laser parameters are: $2 \mu \mathrm{J} /$ pulse, $1030 \mathrm{~nm}, 250 \mathrm{fs}, 100 \mathrm{kHz}, \mathrm{NA}=0.6$, laser polarization $\perp$ to the writing direction. Measurements were performed at room temperature. Inset: initial retardance, measured before any annealing, according to the writing speed. (b) FEG-SEM, Secondary electron micrographs of the cross section of laser tracks for $v=1 \mathrm{~mm} / \mathrm{s}$ (upper) and $0.01 \mathrm{~mm} / \mathrm{s}$ (lower speed). 
Writing speed $v$ is a key factor for formation of nanogratings, as it directly relates to the overlap between two subsequent pulses. In general, it can be estimated by the formula $1-v /\left(f^{*} D\right)$, where $v$ is the writing speed, $f$ is the repetition rate and $D$ is the laser beam diameter [26]. According to previous results, a decrease in writing speed yields to a higher overlap rate, which further creates a higher number of nanogratings with shorter average spacing [28]. The results shown in Figure $2 b$ are in agreement with these results. Indeed, the spacing of nanogratings $(\Lambda)$ is decreased from $\sim 481 \pm 10 \mathrm{~nm}$ to $\sim 256 \pm 10 \mathrm{~nm}$ as the writing speed $v$ is decreased from $1 \mathrm{~mm} / \mathrm{s}$ to $0.01 \mathrm{~mm} / \mathrm{s}$. At the same time, by comparing the thermal behavior of all samples with different writing speeds in Figure $2 \mathrm{a}$, the sample inscribed by fast writing speed $(v=10 \mathrm{~mm} / \mathrm{s})$ demonstrates the highest thermal stability, accompanied with a sharp decay at $1100{ }^{\circ} \mathrm{C}$. It completely annealed out after $30 \mathrm{~min}$ at $\sim 1210^{\circ} \mathrm{C}$. This temperature is slightly higher than other samples inscribed at lower writing speeds. However, in view of Figure $2 \mathrm{a}, \mathrm{b}$, whether there is a correlation between thermal stability of fs-Type II nanogratings and nanogratings spacing still need further investigations and in particular a thorough analysis on the impact of nanolayers porosity (filling factor, core size). These results are shortly commented in the last section of the discussion.

\subsection{Impact of $\mathrm{Cl}$ and $\mathrm{OH}$ Impurities}

To reveal the impact of $\mathrm{Cl}$ and $\mathrm{OH}$ impurities on writing kinetics of fs-Type II modifications and their thermal behavior, five silica glass samples fabricated by different processes were studied. Based on the classification proposed by Brückner in 1970 [29], we categorized samples into four types as shown in the inset of Figure 3a: Type I silica is fused from natural quartz by electrical melting and its commercial name is Infrasil $301{ }^{\circledR}(\mathrm{OH}<8 \mathrm{ppm} ; \mathrm{Cl}<0.15 \mathrm{ppm})$. Type II silica is fused from natural quartz by plasma flame fusion and contains $380 \mathrm{ppm} \mathrm{OH}$ and $<1 \mathrm{ppm} \mathrm{Cl}$. Type III (Suprasil CG ${ }^{\circledR}$; Spectrosil $2000^{\circledR}$ ) and Type IV silica (Suprasil $\mathrm{F} 300^{\circledR}$ ) were synthetic and were prepared respectively, by electrical melting, or plasma-activated chemical vapor deposition (PCVD). The main similar point between types III and IV silica is the $\mathrm{Cl}$ content, on the order of $100 \mathrm{ppm}$ [29], while the most significant difference is the $\mathrm{OH}$ content: which is $400-1000 \mathrm{pm}$ in the former (wet sample) and $<3 \mathrm{ppm}$ in the later (dry sample) [30]. In addition, due to different raw materials used for silica glass production, that is natural quartz for Type I and II silica and synthetic precursors for Type III and IV silica, the latter are expected to be purer than the formers in terms of trace impurities, such as $\mathrm{Al}$, etc. while containing higher level of $\mathrm{Cl}$. Again, impurity contents for the various silica types are summarized in Table 1. 


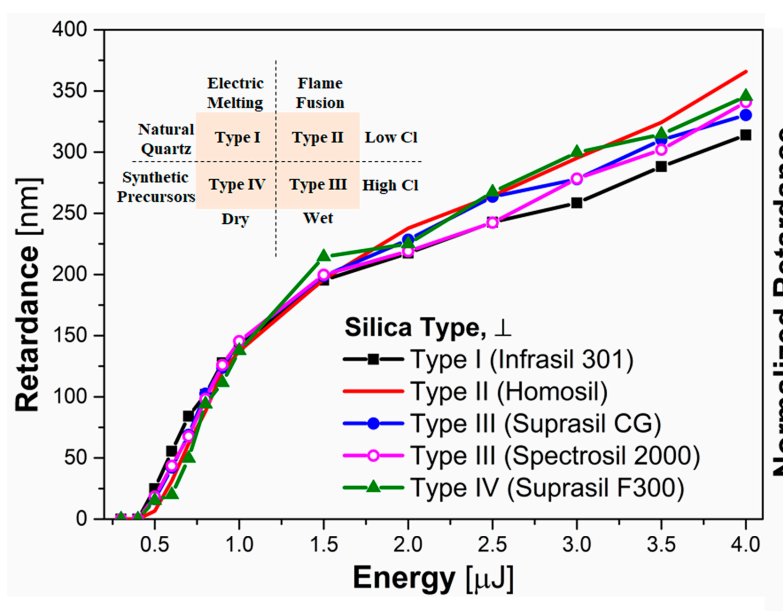

(a)

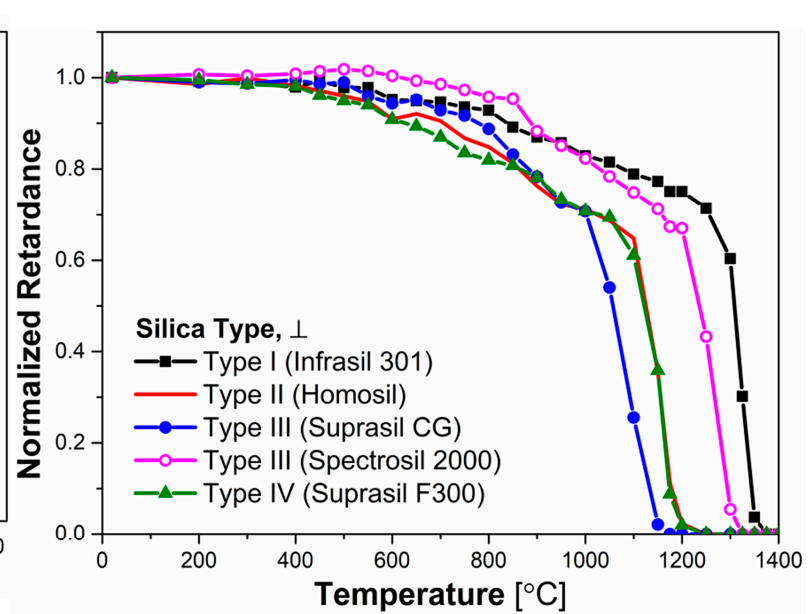

(b)

Figure 3. (a) Retardance as a function of pulse energy for $\mathrm{SiO}_{2}$ glasses: Type I (Infrasil 301 ${ }^{\circledR}$ ), II (Homosil ${ }^{\circledR}$ ), III (Suprasil CG ${ }^{\circledR}$ and Spectrosil 2000 ${ }^{\circledR}$ ), and IV (Suprasil F300 ${ }^{\circledR}$ ). Laser parameters are: $1030 \mathrm{~nm}, 250 \mathrm{fs}, 100 \mathrm{kHz}, 100 \mu \mathrm{m} / \mathrm{s}, \mathrm{NA}=0.6$, laser polarization $\perp$ to writing direction. Inset: category and characteristics of sample; (b) Normalized retardance $\left(R_{\text {norm }}\right)$ as a function of temperature for all $\mathrm{SiO}_{2}$ glasses. Pulse energy is $2 \mu \mathrm{J} /$ pulse and other laser conditions are same mentioned above. The measurements were performed at room temperature.

Figure 3a shows the retardance values measured for all investigated silica glasses, manufactured by the different techniques explained above, as a function of the laser pulse energy. The first interesting result is that there was no variation of the T2 threshold $(0.4 \mu \mathrm{J} / \mathrm{pulse})$ with respect to the glass manufacturing technique used. Each sample exhibited a similar trend in their writing kinetics (i.e., retardance versus pulse energy). In all cases the retardance $R$ was found to increase sharply from $0 \mathrm{~nm}$ to $200 \mathrm{~nm}$ in the $0.4-1.5 \mu \mathrm{J} /$ pulse energy domain. However, for higher pulse energies, up to $4 \mu \mathrm{J} / \mathrm{pulse}$ the retardance increased more slowly. From the results of Figure 3a, it can be stated that the origin of increasing $\mathrm{R}$ for all samples is similar, i.e., the formation of a periodic array of porous nanoplanes isolated by non-porous glass [4,7], cooperating to form birefringence [4,31]. Furthermore, it is also reasonable to conclude that the impact of fabrication techniques and impurities content on the writing kinetics of fs-Type II modifications for all silica samples is not significant, which agrees well with results reported in Reference [16].

Figure $3 \mathrm{~b}$ displays the evolution of the normalized retardance $\left(R_{\text {norm }}\right)$ of all silica glasses as a function of the annealing temperature. In this Figure, it can be found that retardance values for all samples started to decay at $400{ }^{\circ} \mathrm{C}$. After the step at which the silica samples were kept at $1025^{\circ} \mathrm{C}$ for $30 \mathrm{~min}$, the decay of normalized retardance was $\sim 32 \%$ for Types II, III (Suprasil CG ${ }^{\circledR}$ ), and IV silica, while only $\sim 19 \%$ for Types I and III (Spectrosil $2000^{\circledR}$ ) silica. After this step, a sudden drop of retardance is observed. For type III silica (Suprasil $C G^{\circledR}$ ), which is the sample to exhibit this feature at the lowest temperature, no retardance could be detected after $1175^{\circ} \mathrm{C}$. For Type II and IV silica, normalized retardance started to diminish drastically at $1075{ }^{\circ} \mathrm{C}$ and became hard to measure at $1225^{\circ} \mathrm{C}$, which was $50^{\circ} \mathrm{C}$ higher than Type III. Compared with Type II, III (Suprasil CG ${ }^{\circledR}$ ) and IV, Type I and III (Spectrosil 2000 ${ }^{\circledR}$ ) glass exhibited a better thermal stability and a similar decreasing trend. The normalized retardance kept decreasing slowly to $\sim 75 \%$ until $\sim 1300{ }^{\circ} \mathrm{C}$ and there is a very sharp erasure process after that. Finally, the normalized retardance of Type III (Spectrosil $2000^{\circledR}$ ) and I silica could not be detected after $1320^{\circ} \mathrm{C}$ and $1400{ }^{\circ} \mathrm{C}$ respectively, indicating that the fs-Type II modifications of these two samples were completely erased. It is worth pointing out that these values are beyond the estimated glass transition temperature of $1260^{\circ} \mathrm{C}$ for Type I fused quartz with low $\mathrm{OH}$ and aluminum contents [32]. 
Now, from Figure $3 \mathrm{~b}$ and by looking at the evolution of $R_{n o r m}$ as a function of temperature, some typical characteristics can be revealed. At the same OH levels, by comparing Type I (Infrasil $301^{\circledR}$, $\mathrm{Cl}<0.15 \mathrm{ppm}$ ) with Type IV (Suprasil F300 ${ }^{\circledR}, \mathrm{Cl} \sim 2500 \mathrm{ppm}$ ) silica or Type II (Homosil ${ }^{\circledR}, \mathrm{Cl}<1$ ppm) with Type III (Spectrosil $200{ }^{\circledR}, \mathrm{Cl}<0.15$ ppm; Suprasil CG ${ }^{\circledR}, \mathrm{Cl} \sim 2500$ ppm) silica, we can find that silica glasses produced by less pure natural quartz with the lower level of $\mathrm{Cl}$ all demonstrate the better thermal stability than the ones made from synthetics precursor. This indicates that high level of $\mathrm{Cl}$ would be one factor to deteriorate the overall thermal stability of fs-Type II modifications. Similarly, by comparing Type I (Infrasil $301{ }^{\circledR}, \mathrm{OH}<8$ ppm) with Type II (Homosi ${ }^{\circledR}, \mathrm{OH} \sim 380 \mathrm{ppm}$ ) silica or Type IV (Suprasil F300 ${ }^{\circledR}, \mathrm{OH} \sim 0.1 \mathrm{ppm}$ ) with Type III (Suprasil CG ${ }^{\circledR}, \mathrm{OH} \sim 830 \mathrm{ppm}$ ) silica, it is found that dry glasses demonstrate a higher thermal stability than wet glasses when produced by the same precursor material. From these observations, one first conclusion to be drawn is that fs-Type II modifications in dry silica glass with lower levels of $\mathrm{Cl}$, such as Type I silica (Infrasil $\left.{ }^{\circledR}\right)$ in this study, would exhibit a better thermal stability. We note also that $\mathrm{Cl}$ has a stronger impact than $\mathrm{OH}$ (for a fixed concentration) on the thermal stability.

\subsection{Influence of $\mathrm{GeO}_{2}$ Content}

To study the influence of $\mathrm{GeO}_{2}$ content on writing kinetics and thermal stability of fs-Type II modifications, several $x \mathrm{GeO}_{2}-(1-x) \mathrm{SiO}_{2}$ glasses with various $\mathrm{GeO}_{2}$ concentrations ranging from $1.9 \mathrm{~mole} \%$ to 16.9 mole\% were studied in this work. This concentration range is typical for standard optical fibers from single mode fibers like SMF28 (typ. 4 mole $\% \mathrm{GeO}_{2}$ ) to multimode fibers. These samples are optical fiber preforms. They were all manufactured by plasma chemical vapor deposition (PCVD) with low $\mathrm{OH}$ contents ( $<0.1 \mathrm{ppm})$ and high level of $\mathrm{Cl}(\sim 2000 \mathrm{ppm})$.

Figure 4 a displays the retardance values as a function of pulse energy for the four germanosilicate glasses investigated. Results of pure $\mathrm{SiO}_{2}\left(\right.$ Suprasil $\left.\mathrm{CG}^{\circledR}\right)$ is added to serve as a reference. Insets are two microscope images taken between crossed polarizers that reveal the formation of birefringence. The left inset was made using a full order waveplate and highlights the slow axis orientation which flips of $90^{\circ}$ (from yellow to blue color) when the writing laser polarization was changes from $x$ to $y$ orientation. This signature of polarization dependent birefringence confirms indirectly the formation of nanogratings, which have been previously confirmed by SEM [17]. As it can be seen, the threshold T2 [7], related to formation of nanogratings with form birefringence, is about $0.4 \mu \mathrm{J}$ for all tested samples in our experimental conditions, which is the same value of the T2 threshold of pure silica samples shown in Figure 3a. It should also be noted that we did not observe any variation of T2 with the increasing content of $\mathrm{GeO}_{2}$ in the investigated range. From $0.4 \mu \mathrm{J}$ to $1 \mu \mathrm{J}$, the evolution of $R$ as a function of pulse energy for all samples nearly is identical. For higher pulse energies, the slower growth of retardance of all samples can be found. In addition, from $1 \mu \mathrm{J}$ to $4 \mu \mathrm{J}$, it has been reported that overall magnitude of $x \mathrm{GeO}_{2}-(1-x) \mathrm{SiO}_{2}$ binary glasses is higher than retardance values of pure $\mathrm{SiO}_{2}$ sample due to a higher amount of glass decomposition within nanolayers. Such higher form birefringence is also observed in $\mathrm{GeO}_{2}$ glass [20] or $\mathrm{GeO}_{2}$ doped glasses [19] and is explained by smaller pore size of $\mathrm{GeO}_{2}$ but a higher decomposition level (resulting in a higher porosity filling factor) in $\mathrm{SiO}_{2}-\mathrm{GeO}_{2}$ [17] and thus stronger birefringence response [20]. However, opposite trend of writing kinetics has also been observed, showing that the higher the $\mathrm{GeO}_{2}$ content [17], the lower the retardance could be obtained when nanogratings were inscribed by the higher repetition rate $(500 \mathrm{kHz})$, writing speed $(0.5 \mathrm{~mm} / \mathrm{s})$, and higher pulse duration (300 fs). Further systematic study is needed to reveal the impact of writing parameters on fs-Type II modifications in germanosilicate glasses. 


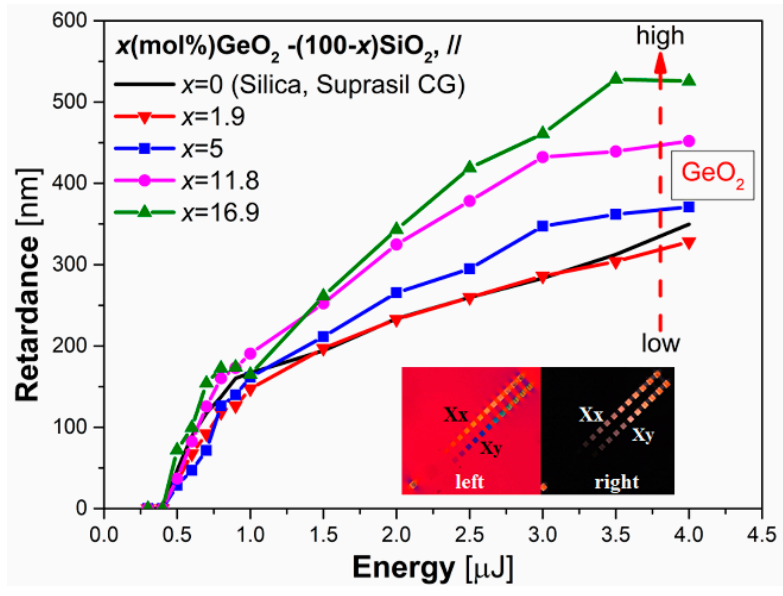

(a)

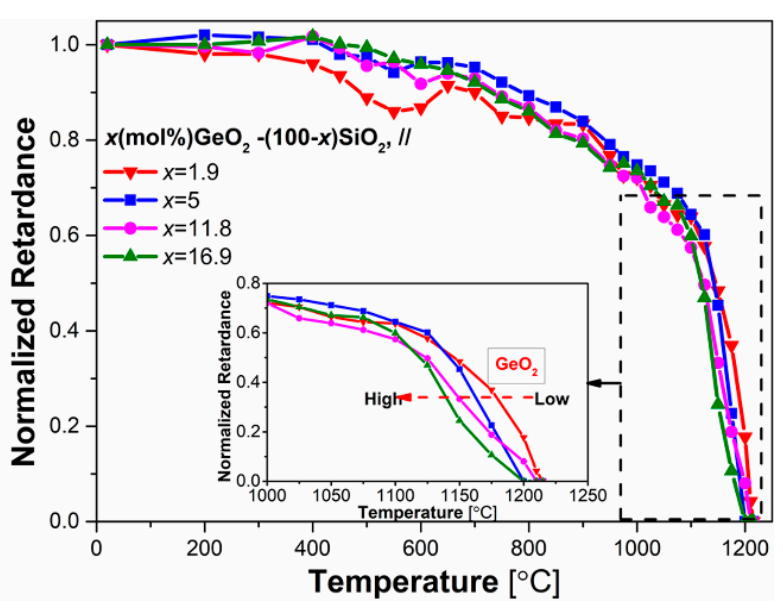

(b)

Figure 4. (a) Retardance as a function of pulse energy for $x \mathrm{GeO}_{2}-(1-x) \mathrm{SiO}_{2}$ glasses $(x=1.9$ to 16.9 mole\%). Inset graph of the sample $16.9 \mathrm{GeO}_{2}-83.1 \mathrm{SiO}_{2}$ glass: left: optical microscope (bottom light illumination) cross a full-wave plate, polarizer, and analyzer; right: optical microscope (bottom light illumination) cross polarizer and analyzer; (b) Normalized retardance $\left(R_{\text {norm }}\right)$ as a function of temperature for $x \mathrm{GeO}_{2}-(1-x) \mathrm{SiO}_{2}$ glasses $(x=1.9$ to 16.9 mole\%). Pulse energy is $2 \mu \mathrm{J} / \mathrm{pulse}$. Laser parameters are: $1030 \mathrm{~nm}, 250 \mathrm{fs}, 100 \mathrm{kHz}, 100 \mu \mathrm{m} / \mathrm{s}, \mathrm{NA}=0.6$, polarization // to writing direction.

Figure $4 \mathrm{~b}$ displays the normalized retardance $R_{\text {norm }}$ of germanosilicate glasses as a function of annealing temperature and shows some characteristic features. In this experiment, we also thermally treated samples written at $2.0 \mu \mathrm{J} /$ pulse, to induce fs-Type II modifications. As we can see, at the beginning, there is a slight increase of the retardance value from $600{ }^{\circ} \mathrm{C}$ to $800{ }^{\circ} \mathrm{C}$, and it is more obvious for germanosilicate glasses with less $\mathrm{GeO}_{2}$ content. Similar behavior of the birefringence has been observed in $\mathrm{SiO}_{2}[9,24], 50 \mathrm{SiO}_{2}-50 \mathrm{Al}_{2} \mathrm{O}_{3}$ pellet [24] and slightly Ge-doped optical fibers [8]. Briefly, it is assumed that this observed unexpected increase is related to some contribution of residual part of Type I (defects, densification, and related stress), which erased at low temperature, resulting in a higher birefringence response [24]. As the annealing temperature increases, the induced stress relaxes gradually, lessening the refractive index and further decreasing retardance. Finally, above $1100{ }^{\circ} \mathrm{C}$, retardance diminishes dramatically, and no birefringence can be found after $\sim 1200^{\circ} \mathrm{C}$ annealing. From the inset of Figure $4 b$, it should be also noted that the "erasing slope" is inversely dependent on the $\mathrm{GeO}_{2}$ concentration and increases from $1150{ }^{\circ} \mathrm{C}$ to $1200{ }^{\circ} \mathrm{C}$ as $\mathrm{GeO}_{2}$ decreases from 16.9 mole $\%$ to $1.9 \mathrm{~mole} \%$. Such result matches with the estimated glass transition temperature $\left(\mathrm{T}_{\mathrm{g}}\right)$ for germanosilicate glasses fabricated by Sol-gel technique with different $\mathrm{GeO}_{2}$ content [33]. In addition, it is also generally accepted that viscosity of glass is reduced by the high level of $\mathrm{OH}$ concentration, which further reduces the glass transition temperature $\left(\mathrm{T}_{\mathrm{g}}\right)$ [33]. Therefore, due to the very fact that samples in our case were fabricated with less $\mathrm{OH}$ content and the fact that germanosilicate glasses are composed of an interpenetrated and interconnected structure of $\mathrm{SiO}_{4}$ and $\mathrm{GeO}_{4}$ tetrahedral units [34], viscosity of glass is expected to change slowly as the concentration of $\mathrm{GeO}_{2}$ varies from 1.9 mole $\%$ to 16.9 mole $\%$. This is confirmed by our viscosity measurements made in two of these samples shown in Figure $4 \mathrm{~b}$ (red and blue curves). It explained why incorporating $\mathrm{GeO}_{2}$ has less impact on overall thermal behavior of all germanosilicate glasses in comparison with pure silica glasses (especially, Type II and IV silica) presented Figure $3 b$.

\subsection{Impact of Dopants}

In this part, the impact of dopants on thermal stabilities of fs-Type II modifications is discussed. In addition to the thermal behavior of the pure silica (Infrasil $301^{\circledR}$ ) and the germanosilicate glasses presented in this work, results of titania-silicate glass $\left(\mathrm{ULE}^{\circledR} ; 7 \mathrm{~mole} \% \mathrm{TiO}_{2}\right.$ ) and aluminoborosilicate 
(Borofloat $33^{\circledR} ; 81$ mole $\% \mathrm{SiO}_{2}, 13$ mole $\% \mathrm{~B}_{2} \mathrm{O}_{3}, 4$ mole $\% \mathrm{Na}_{2} \mathrm{O} / \mathrm{K}_{2} \mathrm{O}, 2$ mole $\% \mathrm{Al}_{2} \mathrm{O}_{3}$ ) are also collected and compared.

Figure 5 a shows the normalized retardance $\left(R_{\text {norm }}\right)$ as a function of temperature. The thermal stability was studied through an annealing experiment of isochronal ( $\delta t=30 \mathrm{~min})$ annealing steps $\left(\Delta \mathrm{T}=50^{\circ} \mathrm{C}\right.$ or $\left.25^{\circ} \mathrm{C}\right)$. Note that the thermal stability is related to a couple $(\mathrm{t}, \mathrm{T})$ and thus related to a thermal energy often called demarcation energy that is usually written as $\mathrm{k}_{\mathrm{B}} \cdot \mathrm{T} \cdot \ln \left(\mathrm{k}_{0} \cdot \mathrm{T}\right)$ for simple cases [35] where $\mathrm{k}_{0}$ is the pre-exponential factor in the Arrhenius rate constant of the erasure reaction and $\mathrm{k}_{\mathrm{B}}$ is the Boltzmann constant. If you determine the $\mathrm{k}_{0}$ value using multiple isothermal or isochronal annealing experiments both isothermal and isochronal accelerated ageing are equivalent and bring similar information's allowing also the possibility to perform reliable lifetime prediction. In our case, the curves in Figure 5a represents the "stability curve" provided that the criterion $\left(\delta t \cdot \mathrm{k}_{0}\right)^{-(\Delta \mathrm{T} / \mathrm{Tmax})} \ll 1$ is fulfilled [35] where $\mathrm{k}_{0}$ is the pre-exponential factor in the Arrhenius rate constant of the erasure reaction. For nanogratings written in silica, $\mathrm{k}_{0}$ has been estimated to be around de $5 \times 10^{5}-5 \times 10^{7} \mathrm{~s}^{-1}$ [36] depending on the laser writing parameters. So, when this criterion is respected, each point can be considered independent of each other. If the criterion is not fulfilled this means that our measurements are slightly under-estimating the real thermal stability.

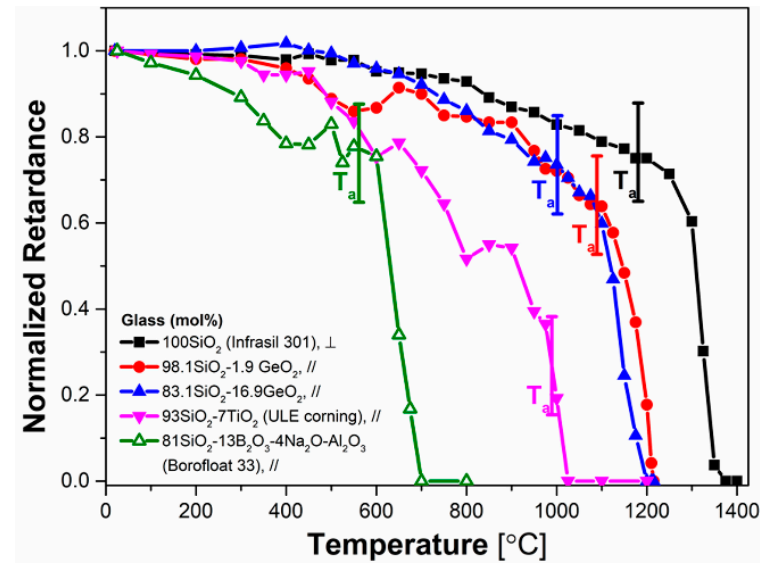

(a)

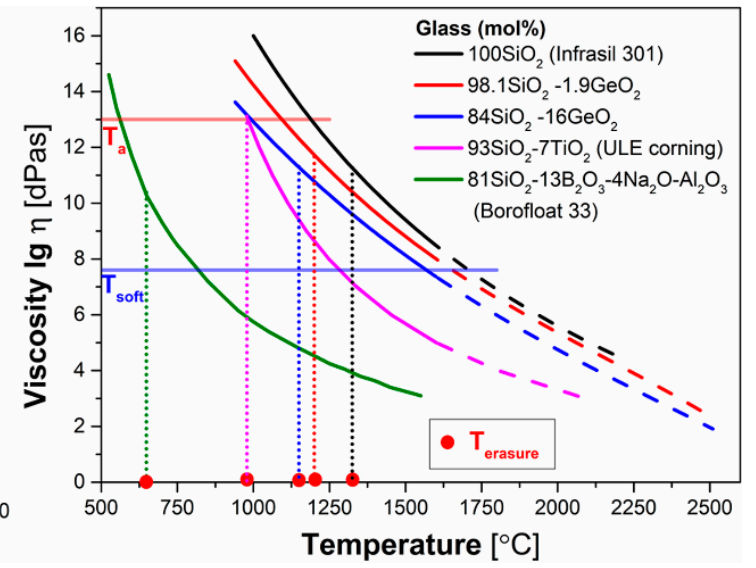

(b)

Figure 5. (a) Normalized retardance $\left(R_{\text {norm }}\right)$ as a function of annealing temperature $T$ for $\mathrm{SiO}_{2}$ (Infrasil $\left.301{ }^{\circledR}\right), 1.9 \mathrm{GeO}_{2}-98.1 \mathrm{SiO}_{2}, 16.9 \mathrm{GeO}_{2}-83.1 \mathrm{SiO}_{2}, 93 \mathrm{SiO}_{2}-7 \mathrm{TiO}_{2}$ (ULE ${ }^{\circledR}$ ), and $81 \mathrm{SiO}_{2}-13 \mathrm{~B}_{2} \mathrm{O}_{3}-4 \mathrm{Na}_{2} \mathrm{O} / \mathrm{K}_{2} \mathrm{O}-2 \mathrm{Al}_{2} \mathrm{O}_{3}$ (Borofloat $33^{\circledR}$ ). (b) Viscosities of glasses with different compositions as a function of temperature (dash line: extrapolated part). Annealing temperature $\left(\mathrm{T}_{\mathrm{a}}\right)$ is defined when $\log (\eta)=13 \mathrm{dPa} \cdot \mathrm{s}$. Softening temperature $\left(\mathrm{T}_{\text {soft }}\right)$ is defined when $\log (\eta)=7.6 \mathrm{dPa} \cdot \mathrm{s}$. Erasure temperature ( $\left.\mathrm{T}_{\text {erasure}}\right)$ is defined at half-amplitude of the final erasure slope of $R_{\text {norm }}(T)$.

As can be seen from Figure $5 a, R_{\text {norm }}$ of $\mathrm{ULE}^{\circledR}$ and Borofloat $33^{\circledR}$ first decreases smoothly until $600{ }^{\circ} \mathrm{C}$, leading to a $20 \%$ decrease for both two samples. At higher temperatures, the decrease in $R_{\text {norm }}(\mathrm{T})$ is accelerated and neither retardance nor refractive index contrast can be found at $650{ }^{\circ} \mathrm{C}$ for Borofloat $33^{\circledR}$ and at $1025^{\circ} \mathrm{C}$ for $\mathrm{ULE}^{\circledR}$, respectively. The studies of mechanisms leading to decay in retardance at high temperature is exemplified in Reference [24] and is attributed to the erasure of point defects below $500{ }^{\circ} \mathrm{C}$. Then there are at least two additional contributions: the first one (intermediate temperature range, typ. $0.8 \mathrm{~T}_{\mathrm{a}}$ to $\mathrm{T}_{\mathrm{a}}$ ) is related to the stress-induced birefringence generated inside and outside the nanolayers; the second one (sharp final decay above $T_{a}$ ) is related to the nanotexturation itself (porosity and periodicity) leading to form birefringence. For germanosilicate glasses, the sharp decay process starts to take place at $1100{ }^{\circ} \mathrm{C}$ and retardance cannot be measured at $\sim 1200{ }^{\circ} \mathrm{C}$, showing a better thermal stability than $\mathrm{ULE}^{\circledR}$ and Borofloat $33^{\circledR}$. For pure silica (Infrasil $301^{\circledR}$ ), from $\sim 1300{ }^{\circ} \mathrm{C}$ and above, a steep decrease of $R_{\text {norm }}$ occurs up to $1400{ }^{\circ} \mathrm{C}$ for $30 \mathrm{~min}$. To sum up, thermal stability of fs-Type II modifications on the various samples can be classified as follow (from higher to lower 
thermal stability): $100 \mathrm{SiO}_{2}>1.9 \mathrm{GeO}_{2}-98.1 \mathrm{SiO}_{2}>16.9 \mathrm{GeO}_{2}-83.1 \mathrm{SiO}_{2}>93 \mathrm{SiO}_{2}-7 \mathrm{TiO}_{2}>81 \mathrm{SiO}_{2}-13$ $\mathrm{B}_{2} \mathrm{O}_{3}-4 \mathrm{Na}_{2} \mathrm{O} / \mathrm{K}_{2} \mathrm{O}-2 \mathrm{Al}_{2} \mathrm{O}_{3}$.

Viscosities $\eta$ of glasses with dopants were plotted as a function of temperature (Figure $5 b$ ). The viscosities of Infrasil $301{ }^{\circledR}, \mathrm{ULE}^{\circledR}$, and Borofloat $33^{\circledR}$ were obtained from the commercial data. The viscosity of germanosilicate glasses was measured and extrapolated above $1500{ }^{\circ} \mathrm{C}$. The annealing temperature $\left(T_{a}\right)$ of the glasses, related to the glass structural relaxation, were determined from the curves when the $\log (\eta)$ reaches $13 \mathrm{dPa} \cdot \mathrm{s}$. From the Figure $5 b$, it is evident that viscosities $\eta(T)$ of all the samples decrease when temperature increases. In addition, it is clear that pure silica (Infrasil $301^{\circledR}$ ) has the highest viscosities and $\mathrm{T}_{\mathrm{a}}\left(1180^{\circ} \mathrm{C}\right)$ compared with other silicate glasses. Furthermore, compared with pure silica, the viscosity and $\mathrm{T}_{\mathrm{a}}$ of $\mathrm{GeO}_{2}$-doped glass samples only slightly decreases with the increase of $\mathrm{GeO}_{2}$ content, indicating that there are minor changes of the glass network structure after doping with $\mathrm{GeO}_{2}$. However, when it comes to titania-silicate glass and aluminoborosilicate, the viscosities and $\mathrm{T}_{\mathrm{a}}$ decreases drastically, showing that high doping levels of titania oxide $\left(\mathrm{TiO}_{2}\right)$ or boron trioxide $\left(\mathrm{B}_{2} \mathrm{O}_{3}\right)$ would significantly modify the initial silica glass network structure. Combined with the results shown in Figure $5 \mathrm{a}$, we found that a steep decay always starts to take place after $\mathrm{T}_{\mathrm{a}}$, typ. around $\mathrm{T}_{\text {erasure }}$ (reported in Figure $5 b$ ), and is always fully erased for a temperature slightly lower than $\mathrm{T}_{\text {soft }}$. So, the thermal stability of fs-Type II modifications seems to be correlated qualitatively but not quantitatively to their $T_{a}$. A more accurate view might be related to the temperature corresponding to a glass structural relaxation time $\tau(T)$ of $30 \mathrm{~min}$, usually defined by $\tau(T)=\eta(T) / G(T)$, with $G$ being the glass shear modulus.

\section{Discussion}

In agreement with Reference [37], fs-Type II modifications or nanogratings formation in silica or glass is limited by internal structural relaxation of glass when using high pulse energy or high repetition rate. In our studies, the thermal stability or nanogratings erasure, also might be related to the glass structural relaxation $\tau(\mathrm{T})$ but this is likely more complex due to the multiple steps' erasure mechanism. Indeed, the nanogratings erasure relates to oxide decomposition/formation in $\mathrm{SiO}_{2}$, nanoscale phase separation in other glasses, oxygen chemical migration/reaction, all taking time. However, they do not depend only on the viscosity e.g., the viscous flow but also mostly the surface tension, are especially important for voids and pores erasure. Especially, at high temperature, chemical migration coefficient and viscosity are strongly interconnected with each other. It explains why "thermal stability" of fs-Type II modifications in silicate glasses is in the same order as their annealing temperature $\left(\mathrm{T}_{\mathrm{a}}\right)$ : the higher $\mathrm{T}_{\mathrm{a}}$, the most stable behavior at high temperature of fs-Type II modifications can be found and expected.

It has been shown that doping titania oxide $\left(\mathrm{TiO}_{2}\right)$ or boron trioxide $\left(\mathrm{B}_{2} \mathrm{O}_{3}\right)$ into silicate glasses would significantly affect the silicate network structure. For instance, complex silicate sheets can be depolymerized into simpler silicate structures by doping with $\mathrm{TiO}_{2}$ [38] and can yield to weak B-O bonds with low bond energies when the glass is doped with $\mathrm{B}_{2} \mathrm{O}_{3}$ [39]. As a result, viscosity and $\mathrm{T}_{\mathrm{a}}$ decrease, making fs-Type II modifications easier to be erased at high temperature as shown in Figure 5a. In addition to that, impurities, such as hydroxyl $(\mathrm{OH})$ and chloride $(\mathrm{Cl})$, are also proven to be another factor influencing the thermal stability of fs-Type II modifications as we shown in Section 3.2. For $\mathrm{OH}$ impurities, it has generally been agreed that water incorporated in glass structure is in the form of hydroxyl ions $(\mathrm{SiOH})$ and the presence of $\mathrm{SiOH}$ in glasses therefore increases the concentration of non-bridging anions, which further decrease the viscosity of glass and thus $T_{a}$ [40]. It explains why fs-Type II modifications in dry glasses (Type I and IV silica) in our study shows better thermal performance than wet glasses (Type II and III silica). Similarly, $\mathrm{Cl}$ as another impurity that relies to the manufacturing process would decrease the viscosity, $\mathrm{T}_{\mathrm{a}}$ and relaxation time of the glass [41], making fs-Type II modifications in Type III and IV silica in our study become less stable.

When it comes to the influence of germanium dioxide $\left(\mathrm{GeO}_{2}\right)$ in Figure $4 b$, we can see that by doping with $\mathrm{GeO}_{2}$ up to approximately $17 \mathrm{~mole} \%$, the thermal behavior of fs-Type II modifications is somewhat similar. It is attributed to the fact that $\mathrm{GeO}_{2}$ and $\mathrm{SiO}_{2}$, when mixed, form a continuous 
random mixture, and the two networks are strongly connected or "interpenetrated" [34]. That is why adding a few mole $\%$ of $\mathrm{GeO}_{2}$ does not change so much viscosity, $\mathrm{T}_{\mathrm{a}}$ and thus thermal stability. However, we also observed, at high temperature, the steep decay to be weakly dependent of $\mathrm{GeO}_{2}$ concentration (inset of Figure $4 \mathrm{~b}$ ) in agreement with our viscosity measurements.

For the impact of writing speed on thermal stability of fs-Type II modifications, it is not easy to draw a conclusion at this step. For example, we cannot say that higher nanogratings spacing induced by slow writing would lead to a better thermal performance of fs-Type II modifications, because of some counter-examples. From the perspective of porosity erasure, at the same level of viscosity and by the same annealing procedures, it would take more time to erase the larger pores rather than the small ones. However, this may not directly be related to porosity or periodicity. It is true that we observed a large difference in thermal stability in the $900-1100{ }^{\circ} \mathrm{C}$ temperature range from Figure $2 \mathrm{a}$, but this difference reduces when the erasure is total, around $1200^{\circ} \mathrm{C}$. This significant difference in retardance we observed might be rather related to stress effects, contributing to our retardance measurements (stress-induced birefringence), which usually relax during a thermal treatment at $0.8-0.9 \cdot \mathrm{T}_{\mathrm{a}}$. Based on Reference [42], higher deposited energy dose (i.e., lower speed) leads to higher cumulative stress: each nanolayer undergoes a net volume expansion [43], which results in some residual compressive stress. Consequently, slow writing speed resulting in more nanolayers per unit of length (i.e., shorter periods) would yield to higher cumulative residual stress and thus stress birefringence values. So following this view, from Figure 2a, we can estimate that low speed writing leads to a high stress induced birefringence, contributing to $40 \%$ of the total retardance, instead of $20 \%$ for high writing speed at $\sim 1100^{\circ} \mathrm{C}$.

\section{Conclusions}

In this work, we mainly investigated the impacts of writing speed, impurities $(\mathrm{Cl}$ and $\mathrm{OH})$, and $\mathrm{GeO}_{2}, \mathrm{TiO}_{2}$ dopants on thermal stability of Type II modifications and their writing kinetics by IR femtosecond laser in silica-based glasses. From this study, we found that the impact of writing speed on $f_{s}$-Type II modifications thermal stability is not intuitive in pure silica. High level of $\mathrm{OH}$ and $\mathrm{Cl}$ impurities would reduce the Type II modifications thermal stability, while causing negligible impact on their writing kinetics. We observed that by adding $\mathrm{GeO}_{2}$ into $\mathrm{SiO}_{2}$ up to 17 mole\%, the thermal stability is only slightly influenced, while the magnitude of the retardance is found to be dependent on $\mathrm{GeO}_{2}$ concentration. By comparing the thermal behavior and viscosity of Borofloat $33^{\circledR}$, $\mathrm{ULE}^{\circledR}, \mathrm{GeO}_{2}-\mathrm{SiO}_{2}$ and $\mathrm{SiO}_{2}$ (Infrasil $301^{\circledR}$ ) glasses, we found that the thermal stability of Type II modifications is partly related to the glass structural relaxation or viscosity but not solely due to additional mechanisms involving nanopores erasure, oxide decomposition/formation, and chemical migration. It also explains the variation of thermal behavior induced by $\mathrm{GeO}_{2}$ and impurities. These results provide a reference work for writing such "Type II fs-IR" modifications on multicomponent silicate fibers to make fiber Bragg gratings with high thermal stability.

Author Contributions: Conceptualization, S.-E.W. and M.L.; data curation, Y.W., H.Y. and M.L.; formal analysis, S.-E.W., M.L., B.P. and M.C.; funding acquisition, M.L.; investigation, S.-E.W., M.C. and M.L.; methodology, M.L., H.Y. and Y.W.; project administration, M.L.; supervision, M.L. and G.-D.P.; Validation, Y.W., M.C., M.L., B.P. and G.-D.P.; visualization, M.L. and S.-E.W.; writing—original draft, S.-E.W.; writing-review and editing, S.-E.W., Y.W., M.C., B.P., M.L. and G.-D.P. All authors have read and agreed to the published version of the manuscript.

Funding: This research was funded by Agence Nationale pour la Recherche, FLAG-IR project, grant number ANR-18-CE08-0004-01 and by CNRS Défi “Instrumentation aux Limites", Ultrabragg project.

Conflicts of Interest: The authors declare no conflict of interest. 


\section{References}

1. Åslund, M.L.; Canning, J.; Canagasabey, A.; De Oliveira, R.A.; Liu, Y.; Cook, K.; Peng, G.-D. Mapping the thermal distribution within a silica preform tube using regenerated fibre Bragg gratings. Int. J. Heat Mass Transf. 2012, 55, 3288-3294. [CrossRef]

2. Baldwin, C.S. Brief history of fiber optic sensing in the oil field industry. In Fiber Optic Sensors and Applications XI; SPIE: Baltimore, MD, USA, 2014.

3. Hill, K.O.; Meltz, G. Fiber bragg grating technology fundamentals and overview. J. Light. Technol. 1997, 15, 1263-1276. [CrossRef]

4. Cavillon, M.; Lancry, M.; Poumellec, B.; Wang, Y.T.; Canning, J.; Cook, K.; Hawkins, T.; Dragic, P.; Ballato, J. Overview of high temperature fibre Bragg gratings and potential improvement using highly doped aluminosilicate glass optical fibres. J. Phys. Photonics. 2019, 1, 042001. [CrossRef]

5. Mihailov, S.J.; Grobnic, D.; Hnatovsky, C.; Walker, R.B.; Lu, P.; Coulas, D.; Ding, H. Extreme environment sensing using femtosecond laser-inscribed fiber Bragg gratings. Sensors 2009, 17, 2909. [CrossRef]

6. Mihailov, S.J. Fiber bragg grating sensors for harsh environments. Sensors 2012, 12, 1898-1918. [CrossRef]

7. Lancry, M.; Poumellec, B.; Canning, J.; Cook, K.; Poulin, J.C.; Brisset, F. Ultrafast nanoporous silica formation driven by femtosecond laser irradiation. Laser Photonics Rev. 2013, 7, 953-962. [CrossRef]

8. Grobnic, D.; Smelser, C.W.; Mihailov, S.J.; Walker, R.B. Long-term thermal stability tests at $1000{ }^{\circ} \mathrm{C}$ of silica fibre bragg gratings made with ultrafast laser radiation. Meas. Sci. Technol. 2006, 17, 1009-1013. [CrossRef]

9. Bricchi, E.; Kazansky, P.G. Extraordinary stability of anisotropic femtosecond direct-written structures embedded in silica glass. Appl. Phys. Lett. 2006, 88, 111119. [CrossRef]

10. Wood, D.; Walker, K.; MacChesney, J.; Simpson, J.; Csencsits, R. Germanium chemistry in the MCVD process for optical fiber fabrication. J. Light. Technol. 1987, 5, 277-285. [CrossRef]

11. Van Uitert, L.G.; Pinnow, D.A.; Williams, J.C.; Rich, T.C.; Jaeger, R.E.; Grodkiewicz, W.H. Borosilicate glasses for fiber optical waveguides. MRS Bull. 1973, 8, 469-476. [CrossRef]

12. Simpson, J.R.; MacChesney, J.B. Optical fibres with an $\mathrm{Al}_{2} \mathrm{O}_{3}$-doped silicate core composition. Electron. Lett. 1983, 19, 261-262. [CrossRef]

13. Reddy, P.H.; Rahman, M.F.A.; Paul, M.C.; Latiff, A.A.; Rosol, A.H.A.; Das, S.; Dhar, A.; Bhadra, S.K.; Dimyati, K.; Harun, S.W. Titanium dioxide doped fiber as a new saturable absorber for generating mode-locked erbium doped fiber laser. Optik. 2018, 158, 1327-1333. [CrossRef]

14. Shibata, S.; Nakahara, M. Fluorine and chlorine effects on radiation-induced loss for $\mathrm{GeO}_{2}$-doped silica optical fibers. J. Light. Technol. 1985, 3, 860-863. [CrossRef]

15. Ainslie, B.J.; France, P.W.; Newns, G.R. Water impurity in low-loss silica fibre. MRS Bull. 1977, 12, $481-487$. [CrossRef]

16. Lancry, M.; Groothoff, N.; Guizard, S.; Yang, W.; Poumellec, B.; Kazansky, P.G.; Canning, J. Femtosecond laser direct processing in wet and dry silica glass. J. Non-Cryst. Solids. 2009, 355, 1057-1061. [CrossRef]

17. Lancry, M.; Canning, J.; Cook, K.; Heili, M.; Neuville, D.R.; Poumellec, B. Nanoscale femtosecond laser milling and control of nanoporosity in the normal and anomalous regimes of $\mathrm{GeO}_{2}-\mathrm{SiO}_{2}$ glasses. Opt. Mater. Express. 2016, 6, 321-330. [CrossRef]

18. Lancry, M.; Desmarchelier, R.; Guth, N.; Zimmerman, F.; Brisset, F.O.; Nolte, S.; Poumellec, B. Porous Nanogratings and Related Form Birefringence in Silicate and Germanate Glasses. In Proceedings of the Bragg Gratings, Photosensitivity, and Poling in Glass Waveguides, Barcelona, Spain, 27-31 July 2014.

19. Lancry, M.; Poumellec, B.; Chahid-Erraji, A.; Beresna, M.; Kazansky, P.G. Dependence of the femtosecond laser refractive index change thresholds on the chemical composition of doped-silica glasses. Opt. Mater. Express. 2011, 1, 711-723. [CrossRef]

20. Lancry, M.; Zimmerman, F.; Desmarchelier, R.; Tian, J.; Brisset, F.; Nolte, S.; Poumellec, B. Nanogratings formation in multicomponent silicate glasses. Appl. Phys. B. 2016, 122, 66. [CrossRef]

21. Poumellec, B. Links between writing and erasure (or stability) of bragg gratings in disordered media. J. Non-Cryst. Solids. 1998, 239, 108-115. [CrossRef]

22. Grobnic, D.; Hnatovsky, C.; Mihailov, S.J. Low loss type II regenerative bragg gratings made with ultrafast radiation. Opt. Express. 2016, 24, 28704-28712. [CrossRef] 
23. Desmarchelier, R.; Poumellec, B.; Brisset, F.; Mazerat, S.; Lancry, M. In the heart of femtosecond laser induced nanogratings: From porous nanoplanes to form birefringence. World J. Nano Sci. Eng. 2015, 5, 115-125. [CrossRef]

24. Wang, Y.; Wei, S.; Cicconi, M.R.; Tsuji, Y.; Shimizu, M.; Shimotsuma, Y.; Miura, K.; Peng, G.-D.; Neuville, D.R.; Poumellec, B.; et al. Femtosecond Laser Direct Writing in $\mathrm{SiO}_{2}-\mathrm{Al}_{2} \mathrm{O}_{3}$ Binary Glasses and Thermal Stability of Type II Permanent Modifications. J. Am. Ceram. Soc.. (under review).

25. The de Sénarmont Compensator. Available online: https://www.olympus-lifescience.com.cn/fr/microscoperesource/primer/techniques/polarized/desenarmontcompensator/ (accessed on 24 January 2020).

26. Fan, C.; Poumellec, B.; Zeng, H.; Lancry, M.; Yang, W.; Bourguignon, B.; Chen, G. Directional writing dependence of birefringence in multicomponent silica-based glasses with ultrashort laser irradiation. J. Laser Micro/Nanoeng. 2011, 6, 158-163. [CrossRef]

27. Witcher, J.J.; Reichman, W.J.; Fletcher, L.B.; Troy, N.W.; Krol, D.M. Thermal annealing of femtosecond laser written structures in silica glass. Opt. Mater. Express. 2013, 3, 502-510. [CrossRef]

28. Dogan, Y.; Madsen, C.K. Optimization of ultrafast laser parameters for 3D micromachining of fused silica. Opt Laser Technol. 2019, 123, 105933. [CrossRef]

29. Brueckner, R. Properties and structure of vitreous silica. I. J. Non-Cryst. Solids. 1970, 5, 123-175. [CrossRef]

30. Bennett, H.E.; Guenther, A.H.; Newnam, B.E.; Soileau, M.J. Laser Induced Damage in Optical Materials: 1988; NIST: Gaithersburg, MD, USA, 1989; pp. 89-90.

31. Bricchi, E.; Klappauf, B.G.; Kazansky, P.G. Form birefringence and negative index change created by femtosecond direct writing in transparent materials. Opt. Lett. 2004, 29, 119-121. [CrossRef]

32. Champagnon, B.; Le Parc, R.; Guenot, P. Relaxation of silica above and below $\mathrm{T}_{\mathrm{g}}$ : Light scattering studies. Philos. Mag. B. 2002, 82, 251-255. [CrossRef]

33. Ho, C.K.; Djie, H.S.; Pita, K.; Ngo, N.Q.; Kam, C.H. Sintering and porosity control of (x) $\mathrm{GeO}_{2}:(1-\mathrm{x}) \mathrm{SiO}_{2}$ sol-gel derived films for optoelectronic applications. Electrochem. Solid-State Lett. 2004, 7, F96-F98. [CrossRef]

34. Huang, Y.Y.; Sarkar, A.; Schultz, P.C. Relationship between composition, density and refractive index for germania silica glasses. J. Non-Cryst. Solids. 1978, 27, 29-37. [CrossRef]

35. Poumellec, B.; Lancry, M. Kinetics of thermally activated physical processes in disordered media. Fibers 2015, 3, 206-252. [CrossRef]

36. Cerkauskaite, A. Ultrafast Laser Nanostructuring for Photonics and Information Technology. Doctoral Dissertation, University of Southampton, England, UK, 2018.

37. Rudenko, A.; Colombier, J.P.; Itina, T.E. Nanopore-mediated ultrashort laser-induced formation and erasure of volume nanogratings in glass. Phys. Chem. Chem. Phys. 2018, 20, 5887-5899. [CrossRef] [PubMed]

38. Park, H.; Park, J.Y.; Kim, G.H.; Sohn, I. Effect of $\mathrm{TiO}_{2}$ on the viscosity and slag structure in blast furnace type slags. Steel Res. Int. 2012, 83, 150-153. [CrossRef]

39. Cai, Z.; Song, B.; Li, L.; Liu, Z.; Cui, X. Effects of $\mathrm{B}_{2} \mathrm{O}_{3}$ on viscosity, structure, and crystallization of mold fluxes for casting rare earth alloyed steels. Metals 2018, 8, 2018. [CrossRef]

40. McMillan, P.W.; Chlebik, A. The effect of hydroxyl ion content on the mechanical and other properties of soda-lime-silica glass. J. Non-Cryst. Solids. 1980, 38, 509-514. [CrossRef]

41. Haken, U.; Humbach, O.; Ortner, S.; Fabian, H. Refractive index of silica glass: Influence of fictive temperature. J. Non-Cryst. Solids. 2000, 265, 9-18. [CrossRef]

42. Rajesh, S.; Bellouard, Y. Towards fast femtosecond laser micromachining of fused silica: The effect of deposited energy. Opt. Express 2010, 18, 21490-21497. [CrossRef]

43. Champion, A.; Bellouard, Y. Direct volume variation measurements in fused silica specimens exposed to femtosecond laser. Opt. Mater. Express. 2012, 2, 789-798. [CrossRef]

(C) 2020 by the authors. Licensee MDPI, Basel, Switzerland. This article is an open access article distributed under the terms and conditions of the Creative Commons Attribution (CC BY) license (http://creativecommons.org/licenses/by/4.0/). 